\title{
LAS CLAVES ESTETICAS DE OCTAVIO PAZ EN PIEDRA DE SOL
}

\author{
POR \\ JOSE L. MAS \\ California State University
}

Por su importancia dentro de la obra poética de Octavio Paz y por su unidad estructural, Piedra de sol ${ }^{1}$ merece, a nuestro juicio, un estudio particular que se enfoque sobre aspectos específicos de la estética de su autor. Esta estética está contenida en una serie de ideas o postulados sobre la poesía y aparece delineada en el libro El arco y la lira ${ }^{2}$, publicado solamente un año antes que el poema. No es nuestro propósito discutir los valores intrínsecos de la tesis del poeta, la cual para algunos está llena de contradicciones ${ }^{3}$ y para otros encierra valiosos elementos de una estética que ha sido calificada de contemporánea ${ }^{4}$.

Sin embargo, sí nos interesa aludir a principios que consideramos

${ }^{1}$ El poema fue publicado por primera vez en 1957, y desde entonces ha aparecido en diversas ediciones o en compilaciones de la poesía de Octavio Paz. Para este estudio hemos utilizado la versión incluida en Libertad bajo palabra (México: Fondo de Cultura Económica, 1960). Todas las citas del poema serán indicadas en el texto por medio del número de la página entre paréntesis.

${ }^{2}$ Octavio Paz (México: Fondo de Cultura Económica, 1967). Las demás citas de este libro serán indicadas en el texto por medio del número de la página entre paréntesis.

${ }^{3}$ En la obra La divina pareja. Historia y mito en Octavio Paz (México: Ediciones Era, S. A., 1978), su autor, Jorge Aguilar Mora, presenta una valoración e interpretación crítica de la obra ensayística de Octavio Paz. Aunque no se refiere exclusivamente al Arco y la lira, es evidente que rechaza, por contradictorios, muchos de los postulados de la tesis de Octavio Paz, que aparecen discminados en diferentes obras del poeta. Actitud opuesta es la de Monique Lemaître en Octavio Paz. Poesia y poética (México: UNAM, 1976).

${ }^{4}$ Gustavo V. Segade, en su artículo «The Poetics of Octavio Paz: A Contemporary Esthetic», Grito del Sol, año II, libro IV (Berkeley, 1977), hizo un estudio valioso sobre la estética de Octavio Paz. El enfoque de esa publicación inspiró nuestro trabajo y nos ayudó al análisis de muchos de los aspectos del poema, por lo que expresamos nuestro reconocimiento a su autor. 
funcionales dentro del marco conceptual previamente expuesto por Octavio Paz. Vamos a intentar, además, el análisis de su relación con el poema como procedimiento para identificar las claves estéticas que nos permita explicar distintos aspectos del mismo, estructurados en las dualidades punto de vista/intención, ritmo/significado (con referencia al lenguaje), tiempo/imagen, instante/inspiración y no ser/ser, esta última como sostén de lo que Octavio Paz identifica como la función sagrada de la poesía. La posible influencia oriental será mencionada dentro del contexto personal usado por el poeta en el Arco y únicamente con el propósito de ilustrar conceptos que tienen conexión con su pensamiento estético y con el poema.

Es evidente que Octavio Paz en el Arco hace un esfuerzo por rechazar la lógica de Occidente en cuanto a la interpretación de la realidad, fundamentalmente porque está basada en el conflicto de posibilidades contradictorias (tales como permanencia/cambio, ser/no ser, espíritu/ materia) que deben resolverse. En su argumentación nos explica asimismo sus preferencias por el pensamiento oriental, el cual acepta todas esas contradicciones como manifestaciones de una misma realidad que resulta entonces perfilada por la interacción de elementos distintos.

Esta realidad de que nos habla el poeta está regida por la ley eterna de Tao, que comprende todas las relaciones existentes en un determinado momento y que se manifiesta precisamente por la coexistencia simultánea de elementos que pueden ser disímiles. En la tradición oriental este postulado fundamental es la «juntura», es decir, la línea que representa la unidad, pero la cual una vez trazada divide el mundo en dos dualidades: arriba y abajo, izquierda y derecha, es decir, el mundo de los contrarios. Octavio Paz, en el Arco, hace referencia a la pareja de Yin y Yang como los dos ritmos alternantes que forman el Tao, y que no son otra cosa que las dos zonas (luz y sombra) en que resulta dividido el círculo primario ( $w u$ chi) por medio de la «juntura». Como estos contrarios normalmente interaccionan de forma perceptible, su significado no está dado sólo por el conflicto, sino también por la posibilidad de la armonía. Ahora bien, la realidad total, no el círculo, tampoco la juntura, ni ninguna de las dos partes separadamente, sino que está constituida por todas esas cosas funcionando en una relación de dependencia, es decir, como una unidad.

Este planteamiento nos parece obvio como punto de vista de Piedra de sol, poema que esencialmente vislumbra el momento de esa interacción y unidad de los contrarios: 
las paredes

invisibles, las máscaras podridas

que dividen al hombre de los hombres,

al hombre de sí mismo,

se derrumban

por un instante inmenso y vislumbramos

nuestra unidad perdida, el desamparo

que es ser hombres, la gloria que es ser hombres

y compartir el pan, el sol, la muerte,

el olvidado asombro de estar vivos (303-304).

Bajo este esquema lógico, Octavio Paz evita el dilema de escoger entre posibilidades contradictorias los elementos básicos de una estética. Su pensamiento, que se orienta a la unidad, dentro del marco de referencia que se ha planteado, no va a seleccionar elementos individuales que se contradicen, sino que va a buscar a todos simultáneamente:

El pensamiento oriental no ha padecido este horror a lo «otro», a lo que es y no es al mismo tiempo. El mundo occidental es el del «esto o aquello»; el oriental es el del «esto y aquello» y aun el del «esto es aquello» (Arco, 102).

De tal manera, la llave que nos abre la puerta a un acercamiento a todas las cosas será el descubrimiento de lo «otro». Tal como lo discute Octavio Paz en el Arco, si tú eres yin el otro es yang, y si tú eres yang el otro es yin, pues cada uno contiene al otro y también determina su forma. Mas esta ideal interdependencia de contrarios no debe entenderse como la síntesis hegeliana, porque el desarrollo cronológico es fundamental en la dialéctica de Hegel y la simultaneidad de la existencia de los contrarios es esencial para entender el concepto de yin y yang.

Puede asegurarse que Piedra de sol es la afirmación de este pensamiento unitario oriental, y que su intención, colocada junto a su punto de vista, va dirigida al descubrimiento de ese «otro» como la única vía propicia para configurar nuestra propia existencia:

nunca la vida es nuestra, es de los otros,

la vida no es de nadie, todos somos

la vida — pan de sol para los otros,

los otros todos que nosotros somos-,

soy otro cuando soy, los actos míos

son más míos si son también de todos;

para que pueda ser he de ser otro,

salir de mí, buscarme entre los otros,

los otros que no son si yo no existo,

los otros que me dan plena existencia (308). 
El concepto de esta dualidad complementaria es típico dentro de la estética de Octavio Paz y representa una de las claves de su expresión poética. El mismo, como hemos dicho, no se plantea en términos de confrontación de contrarios ni tampoco de síntesis de elementos antagónicos. Por eso, cuando el poeta nos habla del lenguaje en la poesía, vuelve a expresar su punto de vista dualista, al destacar la importancia de la relación que existe entre el ritmo y el significado.

Aunque al analizar el lenguaje Octavio Paz llega a la conclusión de que en toda forma de expresión humana, incluyendo la poesía, existe un significado, no por eso deja de restarle importancia al ritmo del poema. Desde luego, se preocupa de aclarar que el ritmo no es sólo rima y medida, sino también que es una dirección que lo hace inseparable del significado:

En el ritmo hay "un ir hacia» que sólo puede ser elucidado si, al mismo tiempo, se elucida qué somos nosotros. El ritmo no es medida ni algo que está fuera de nosotros, sino que somos nosotros mismos los que nos vertebramos en el ritmo y nos disparamos hacia «algo». Así, su contenido verbal o ideológico no es separable. Aquello que dicen las palabras del poeta ya está diciéndolo el ritmo en que se apoyan las palabras (ArCo, 57-58).

Piedra de sol es un poema que ha salido disparado hacia ese "algo» de que nos habla Octavio Paz, y que no es otra cosa que al encuentro de otros y de nosotros mismos mediante una búsqueda. Tal orientación rítmica del poema se afianza primeramente en un vocabulario pletórico de verbos que indican movimientos direccionales, como ir, caminar, seguir, proseguir, apoyados en otros que implican una dialéctica alternante dada por el uso de vocablos indicativos de una caída y de una ascensión, que aparecen durante el curso de la composición. La idea de «un caminar tranquilo» con que comienza el poema se convierte en un «quiero seguir y no puedo» que marca la cesación del movimiento y también el final del poema. Pero la verdadera relación entre el ritmo y el significado hay que buscarla en la naturaleza intrínseca de las palabras.

Para Octavio Paz, las palabras también manifiestan una naturaleza dual y, por consiguiente, responden a una oscilación entre sus características denotativas y connotativas. En el Arco nos explica que cuando las palabras son usadas en exposición, predominan sus cualidades denotativas, es decir, que se orientan hacia un solo y exclusivo significado y culminan en la prosa. Pero cuando las palabras son empleadas poéticamente, sus cualidades connotativas predominan.

En efecto, lo que llamamos prosa está producido cuando utilizamos 
las palabras como signos que apuntan a un solo significado, no importa cuán profundo sea el tema. Por el contrario, cuando las palabras se escogen como símbolos que apuntan a una multiplicidad de significados, no importa lo trivial que sea el asunto, culminan en el organismo poético. Dicho de otra manera: la prosa clarifica su significado mediante la creación de un contexto que tiende a excluir alternativas connotativas. La poesía sigue el camino opuesto, o sea, que clarifica su significado creando un contexto que intenta incluir alternativas connotativas.

Del examen del vocabulario empleado en Piedra de sol nos damos cuenta de que hay un uso insistente de las mismas palabras combinadas por procedimientos diferentes. No hay duda de que tales combinaciones contribuyen a crear ritmos que desempeñan un papel importante en la producción de significados especiales. Podemos comprobar que en ocasiones el uso repetido de la misma palabra, encadenada en una secuencia, amplifica y clarifica el significado total de un contexto que incluye diversas posibilidades connotativas para cada palabra individual. De tal modo, la palabra repetida no sólo crea el ritmo, sino que al mencionarse nuevamente nos abre una nueva posibilidad, como en el de una oración o letanía en que se invocaran conjuros mágicos:

rostro de llamas, rostro devorado,
adolescente rostro, perseguido,
años fantasmas, días circulares
que dan al mismo patio, al mismo muro,
arde el instante y son un solo rostro
los sucesivos rostros de la llama,
todos los hombres son un solo nombre,
todos los rostros son un solo rostro,
todos los siglos son un solo instante
y por todos los siglos de los siglos
cierra el paso al futuro un par de ojos (297).

Otras veces la relación ritmo-significado se produce dentro de una oscilación alternante en que las posibilidades connotativas pasan de una palabra a otra en proceso dialéctico. Por consiguiente, la idea, que es igual a sí misma siempre, no puede ser contemplada en su totalidad: lo que vemos y oímos son las subdivisiones de la idea a través del prisma del poema. Por ejemplo, la imagen de la mujer, que es central en Piedra de sol, se hace imprecisa y en lugar de una manifestación excluyente que intente reflejar una realidad concreta, percibimos la evocación de una multiplicidad de formas que resultan unidas o aprisionadas por el ritmo: 
escritura de fuego sobre el jade, grieta en la roca, reina de serpientes, columna de vapor, fuente en la peña, circo lunar, peñasco de las águilas, grano de anís, espina diminuta y mortal que da penas inmortales, pastora de los valles submarinos y guardiana del valle de los muertos, liana que cuelga del cantil del vértigo, enredadera, planta venenosa,

flor de resurrección, uva de la vida (297).

Estos procedimientos combinatorios, que contienen la relación rítmicaconnotativa de las palabras, van creando un organismo poético que no son otra cosa que las imágenes. Octavio Paz nos dice que «la imagen es una frase en la que la pluralidad de significados no desaparece... La imagen se explica a sí misma. Nada, excepto ella, puede decir lo que quiere decir. Sentido e imagen son la misma cosa. Un poema no tiene más sentido que sus imágenes» (Arco, 107-110). Por tanto, para el poeta la imagen es a la vez el contexto, el marco y también el esqueleto del poema. Es lo que unifica el ritmo y el significado conceptual de las palabras, y de esa forma:

El universo deja de ser un vasto almacén de cosas heterogéneas. Astros, zapatos, lágrimas, locomotoras, sauces, mujeres, diccionarios, todo es una inmensa familia, todo se comunica y se transforma sin cesar, una misma sangre corre por todas las formas y el hombre puede ser al fin su deseo: él mismo. La poesía pone al hombre fuera de sí y, simultáneamente, lo hace regresar a su ser original; lo vuelve a sí. El hombre es su imagen: él mismo y aquel otro. A través de la frase que es ritmo, que es imagen, el hombre - ese perpetuo llegar a seres. La poesía es entrar en el ser (Arco, 113).

Resulta claro entonces que la poesía nos va a revelar al hombre y, en consecuencia, el poeta nos va a hablar de cosas que son a la vez suyas y de su mundo. Ahora bien, en el proceso de hacer el poema, el poeta selecciona de hecho ciertas experiencias personales y las transforma en algo excepcional. Este significado especial se logra porque las imágenes dentro del poema, aunque acoplan realidades que pueden ser opuestas o indiferentes entre sí, las convierten en una revelación trascendente:

Esta revelación es el significado último de todo poema y casi nunca está dicha de manera explícita, sino que es el fundamento de todo 
decir poético. En las imágenes y ritmos se transparenta, más o menos acusadamente, una revelación que no se refiere ya a aquello que dicen las palabras del poema, sino a algo anterior y en lo que se apoyan todas las palabras del poema: la condición última del hombre (Arco, 189).

Según confesión del propio poeta, Piedra de sol refleja tres preocupaciones esenciales: su vida personal, las experiencias de su generación y la búsqueda de una visión del tiempo y de la vida ${ }^{5}$. Desde luego, el poema no es sólo historia, y por eso siempre la realidad de lo anecdótico da paso a la revelación de una secreta intimidad, la cual no va a ocurrir dentro del tiempo cronológico lineal, y por ese motivo consigue identificar a la voz poética con todos. Ella va a reflejar un tiempo y espacio especial en los cuales estas experiencias son capaces de existir siempre, como la evocación de la nostalgia de nuestra esencial soledad humana, que resulta así constantemente recreada:
No hay nada en mí sino una larga herida, una oquedad que ya nadie recorre, presente sin ventanas, pensamiento que vuelve, se repite, se refleja y se pierde en su misma transparencia, conciencia traspasada por un ojo que se mira mirarse hasta anegarse de claridad (300).

Para el poeta, entonces, el evento estético no será un objeto en el espacio ni tampoco un acontecimiento en el tiempo, sino un proceso, una acción, una experiencia localizada en espacio y tiempo arquetípicos. Este espacio y tiempo arquetípicos pueden evocar las experiencias de una generación, como es el caso de Octavio Paz, para quien la realidad del conflicto fratricida de la guerra civil española seguramente tiene un personal significado. Pero lo importante en el poema Piedra de sol es que junto al hecho histórico ocurrido en 1937, el poeta evoca el momento del encuentro amoroso, que es en esencia atemporal y, por tanto, arquetípico. Es a través del acto visto como mito eterno de fertilidad y creación como el tiempo cronológico queda anulado y se hace que la vida y el tiempo

${ }^{5}$ Esta afirmación del poeta apareció en el núm. 55 de La Gaceta (México, 1959) y fue reproducida por Julio Requena en su extenso artículo «Poética del tiempo», incluido por Angel Flores en el libro Aproximaciones a Octavio Paz (México: Joaquín Mortiz, S. A., 1974). 
se fundan y formen un solo bloque, para imaginar así la salvación del hombre:

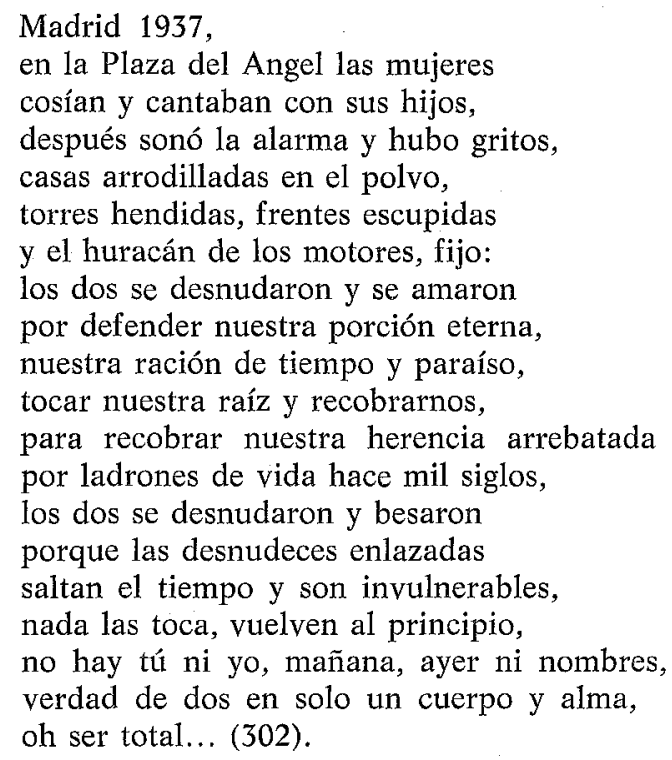

Nos damos cuenta que la relación dual tiempo/imagen se logra en el poema cuando se hacen manifiestos el espacio y tiempo arquetípicos, es decir, mediante lo que pudiéramos llamar la unción de la experiencia. Por medio de las imágenes, las palabras se convierten en un elemento del ritmo de las ideas que recorren el poema, adquiriendo así un significado especial para el poeta y para el lector de la poesía. En Piedra de sol la mención de las palabras vida y tiempo, dentro de imágenes recurrentes, produce el efecto circular de regreso del hombre a sí mismo, que es la evocación final y total del poema. De ese modo las imágenes crean una realidad que destruye la importancia del tiempo medido e intenta convertirla en sólo espacio, es decir, en un mito que perpetúe la experiencia cada vez que es evocada:

oh vida por vivir y ya vivida, tiempo que vuelve en una marejada y se retira sin volver el rostro, lo que pasó no fue pero está siendo y silenciosamente desemboca en otro instante que se desvanece: 
no hay tiempo ya, ni muro: iespacio, espacio, abre la mano, coge esta riqueza, corta los frutos, come de la vida, tiéndete al pie del árbol, bebe el agua! (298-303).

No hay duda de que la palabra aislada no puede producir el poema, sino que son las imágenes las que crean lo poético. Es evidente, entonces, que la relación entre la palabra y la imagen se convierte en una ocurrencia de particular importancia dentro del poema. Ese proceso es el evento estético que pudiéramos llamar el «instante consagrado», y del cual nace el poema, «un mundo completo en sí mismo, tiempo único, arquetípico, que ya no es pasado, ni futuro, sino presente» (Arco, 185187). Octavio Paz se ha referido, en el Arco, al proceso de la captación del instante y a su significación dentro de la poesía especialmente por el vínculo que establece entre el poeta y la "otra voz» que resulta creada por el mismo poema.

Como nos ha dicho, el poeta debe captar el instante con palabras, pero a veces se queda al borde del lenguaje y tiene que descender, ir al fondo, callar, esperar. La creación poética es una actividad que se realiza en soledad, pues antes de escribir el poema no hay nadie ni nada, el poeta está solo consigo mismo; y apenas comienza a escribir, ese yo también desaparece. Piedra de sol evidentemente nos comunica la angustia de la búsqueda del instante, es decir, de lo poético, que como nos dice Octavio Paz, será de creación y de destrucción en una dialéctica que sólo el mismo poema podrá resolver:

busco sin encontrar, busco un instante,
un rostro de relámpago y tormenta
corriendo entre los árboles nocturnos,
rostro de lluvia en jardín a oscuras,
agua tenaz que fluye de mi costado,
busco sin encontrar, escribo a solas,
no hay nadie, cae el día, cae el año,
caigo con el instante, caigo a fondo,
invisible camino sobre espejos
que repiten mi imagen destrozada,
piso días, instantes caminados,
piso los pensamientos de mi sombra,
piso mi sombra en busca de un instante (295-296).

En efecto, el encuentro con el instante va a dar nacimiento al poema y éste va a crear una voz poética, hasta ahora desconocida, que permite al poeta desprenderse de sí mismo para internarse en ese «otro sí mis- 
mo». De una forma paradójica, la búsqueda de la unidad a través del instante abre paso a otra dualidad, establecida ahora entre el poeta que recibe y el nuevo poder que surge de la propia poesía. De tal modo, el instante representa no sólo la esencia del tiempo poético, sino también el proceso por el cual estéticamente la inspiración queda explicada. Independientemente de las experiencias personales que puedan haber sido incluidas dentro del poema, lo que predomina en Piedra de sol es el desarrollo del crecimiento de ese instante como vehículo de creación de la voz poética y del poema:

\author{
El instante se abisma y sobrenada \\ rodeado de muerte, amenazado \\ por la noche y su lúgubre bostezo, \\ amenazado por la muerte viva y enmascarada \\ el instante se abisma y se penetra, \\ como un puño se cierra, como un fruto \\ que madura hacia dentro de sí mismo \\ y a sí mismo se bebe y se derrama \\ el instante translúcido se cierra \\ y madura hacia adentro, echa raíces, \\ crece dentro de mí, me ocupa todo, \\ me expulsa su follaje delirante, \\ mis pensamientos sólo son sus pájaros, \\ su mercurio circula por mis venas, \\ árbol mental, frutos sabor de tiempo (298).
}

Mas, como dice Octavio Paz en el Arco, la experiencia poética es esencialmente abrir las fuentes del ser a través del instante, "un instante y para siempre. Instante en el que somos lo que fuimos y seremos. Nacer y morir. En ese instante somos vida y muerte, esto y aquello» (Arco, 155). Así el poema logra ofrecernos en un instante de incandescencia la visión de lo otro y de la incertidumbre de nuestra condición, que no sólo será la disyuntiva vida o muerte, sino la posibilidad de una existencia total:

miradas que nos miran desde el fondo de la vida y son trampas de la muerte - ¿o es al revés: caer en esos ojos es volver a la vida verdadera?, icaer, volver, soñarme y que me sueñen otros ojos futuros, otra vida, otras nubes, morirme de otra muerte! - esta noche me basta, y este instante 
que no acaba de abrirse y revelarme dónde estuve, quién fui, cómo te llamas, cómo me llamo yo (300-301).

Podemos advertir la dialéctica que para Octavio Paz implica la poesía, y aunque intuimos que el proceso tiende a resolverse en la unidad, ésta siempre parece ilusoria y debatiéndose entre la nostalgia de una vida anterior y el presentimiento de una vida futura. Esta alternativa es la que coloca a la poesía dentro de los límites de lo inefable y traslada la discusión estética a la frontera de lo trascendental. Explorando la posible relación entre la poesía y lo sagrado, Octavio Paz nos dice que la sociedad occidental se ha equivocado de nuevo al tratar de explicar ese nexo por medio del concepto de la «mentalidad primitiva». De ahí que categóricamente rechace esta idea, así como también la de identificar lo sagrado a formas externas, porque ambas, en su opinión, convierten su significado en un objeto:

Las instituciones sociales no son lo sagrado, pero tampoco lo son la "mentalidad primitiva» o la neurosis. Ambos métodos ostentan la misma insuficiencia. Los dos convierten lo sagrado en un objeto... También sería insuficiente una descripción de la experiencia de lo divino como algo exterior a nosotros. Estas experiencias nos incluye y su descripción será la de nosotros mismos (Arco, 121).

Enfocado en estos términos, lo sagrado no puede existir fuera de nosotros mismos, y al igual que todo lo demás, sólo puede ser conocido mediante 1a experiencia. Estas experiencias se convierten, por tanto, en experiencias de nosotros mismos, dentro de la totalidad de la realidad, y se manifiestan mediante una participación o una comunión con esa totalidad. Para la religión, lo sobrenatural es la puerta que nos deja experimentar lo sagrado. Para el amante es la persona amada. Para el proceso que llamamos poesía, la imagen estructurada a través del pensamiento rítmico logrado por medio de la consagración del instante es el umbral que nos introduce en lo sagrado. No importa cuál sea el camino, tal experiencia será siempre una experiencia de lo otro, es decir, una experiencia de nosotros mismos:

La revelación de lo sagrado no es tanto la revelación de un objeto exterior a nosotros - dios, demonio, presencia ajena- como un abrir nuestro corazón o nuestras entrañas para que brote ese «Otro» escondido. La revelación, en el sentido de un don o gracia que viene del exterior, se transforma en un abrirse del hombre a sí mismo (Arco, 140). 
Piedra de sol nos abre el camino hacia esa revelación de lo sagrado siguiendo el proceso dialéctico natural que implica nuestra propia existencia humana. Octavio Paz concede especial importancia dentro de esta experiencia a lo que llama la "caída», que no es otra cosa que la conciencia de la mortalidad. Esta «caída» nos convierte en la nada, pero al nombrarla, en un proceso en el cual lo negativo y lo positivo sé entrecruzan, de la posibilidad de no ser llegamos a la posibilidad de ser. En efecto, ésa es la experiencia a la que nos conduce el poema, al unir caída y ascensión, vida y muerte, no ser y ser:

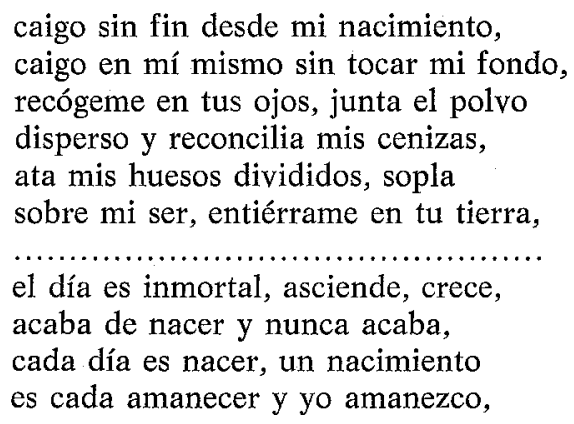

puerta del ser: abre tu ser, despierta, aprende a ser también, labra tu cara, trabaja tus facciones, ten un rostro para mirar mi rostro y que te mire, para mirar la vida hasta la muerte (309-310).

En realidad, la experiencia de lo sagrado no es un punto en el espacio, sino en el tiempo, pero en un tiempo cíclico continuo que de esa forma nos permite experimentar la raíz sagrada de la humanidad. El momento culminante de esta experiencia es el encuentro amoroso, que según Octavio Paz nos permite ver, aunque sea por un instante, la indisoluble unidad de los contrarios. Como nos dice en el Arco y queda confirmado en Piedra de sol, del estado de soledad y angustia en que podamos encontrarnos, y en el cual el mundo parece impenetrable e ininteligible, podemos pasar a otro en el que todo se ilumine y cobre significado:

\section{el mundo cambia}

si dos, vertiginosos y enlazados, caen sobre la yerba: el cielo baja, los árboles ascienden, el espacio sólo es luz y silencio, sólo espacio 
abierto para el águila del ojo, pasa la blanca tribu de las nubes, rompe amarras el cuerpo, zarpa el alma, perdemos nuestros nombres y flotamos a la deriva entre el azul y el verde, tiempo total donde no pasa nada sino su propio transcurrir dichoso (306).

Mediante la presencia del amado y de nuestra unión con él, no sólo se rescata al ser de la nada, sino que cambia el universo, haciendo que todas las presencias vuelvan a la superficie y todo se pueda ver, tocar y palpar. El ser y la apariencia se convierten en una sola cosa y nada está escondido, todo está presente y radiante. De esta transfiguración surge la única posibilidad de un significado trascendente para la vida:

todo se transfigura y es sagrado, es el centro del mundo cada cuarto, es la primera noche, el primer día, el mundo nace cuando dos se besan,

el mundo cambia, encarnan los deseos, el pensamiento encarna, brotan alas en las espaldas del esclavo, el mundo es real y tangible, el vino es vino, el pan vuelve a saber, el agua es agua (303-304).

La experiencia amorosa es entonces una revelación del ser y de la nada, que emerge de nuestra propia participación en el acto y no de una contemplación pasiva. Los elementos del mundo natural aparecen también incorporados al proceso y forman parte, junto a los amantes, de la misma dialéctica continua. En Piedra de sol, estos elementos, unidos al acto amoroso, reflejan el ritmo y el significado del poema y contribuyen a su esencia sagrada. La mujer y la naturaleza son pura presencia en las cuales se oculta el verdadero ser, y de esa forma ambas pueden resultar revelación del ser y de la nada. En ocasiones el ser se manifiesta y los elementos de la naturaleza se integran a esta experiencia:

Voy por tus ojos como por el agua los tigres beben sueño en esos ojos, el colibrí se queda en esas llamas voy por tu frente como por la luna como la nube por tu pensamiento, por tu vientre como por tus sueños, 
tu falda de maíz ondula y canta, tu falda de cristal, tu falda de agua, tus labios, tus cabellos, tus miradas toda la noche llueves, todo el día abre mi pecho con tus dedos de agua, cierra mis ojos con tu boca de agua, sobre mis huesos llueves, en mi pecho hunde raíces de agua un árbol líquido (294).

Pero, según Octavio Paz, el amor desemboca en la muerte, en una muerte de la cual salimos al nacer; por tanto, el sentimiento amoroso es a la vez un morir y un nacer. Por eso los elementos de la naturaleza que antes participaban de nuestra euforia de la vida (sobre todo el agua, tan asociada al nacimiento) se transforman en piedra y polvo, para expresar la imposibilidad del amor y, por lo mismo, la certeza de la muerte:

Ardo sin consumirme, busco el agua

y en tus ojos no hay agua, son de piedra,

$\mathrm{y}$ tus pechos, tu vientre, tus caderas

son de piedra, tu boca sabe a polvo,

tu boca sabe a tiempo emponzoñado,

tu cuerpo sabe a pozo sin salida (299).

Así, la experiencia del amor y de la naturaleza se identifican para expresar lo más sagrado de la existencia humana, es decir, su principio y su fin, convirtiendo el poema en una revelación de nuestra condición original. E1 instante de felicidad que entrevé la experiencia amorosa es una posibilidad de esa unidad total que nos permite recuperar el ritmo natural temporalmente perdido. Por esta vía, el ser puede lograr la trascendencia, pero el problema es que ésta, al igual que otros aspectos de la existencia, es también expresión, movimiento de la temporalidad. Octavio Paz resuelve la aparente contradicción afirmando que tanto la libertad como la temporalidad son trascendencia porque son movimientos del ser, y reduce entonces la incógnita a determinar la dirección de ese movimiento.

En Piedra de sol, la manifestación de ese destino al cual se orienta el movimiento del ser está integrada a la propia intención del poema, que habíamos dicho está dirigida al encuentro de nosotros mismos. De tal manera la trascendencia, o lo que llamamos Dios, no es en el poema un objeto externo o una experiencia exterior a nosotros. Es, por el contrario, el núcleo adonde converge la plenitud de nuestras posibilidades de no ser con el ser, y es también, si se quiere, el centro del círculo 
sagrado trazado por el mismo poema o de la piedra que simboliza su título:

el mundo se despoja de sus máscaras

y en su centro, vibrante transparencia, lo que llamamos Dios, el ser sin nombre, se contempla, en la nada, el ser sin rostro, emerge de sí mismo, sol de soles, plenitud de presencias y de nombres (305).

En la primera edición de Piedra de Sol, que apareció en 1957, se incluyó una nota final explicativa de algunos elementos formales de la composición y de una posible intención de asociar el poema a ciertas tradiciones indígenas explícitamente mencionadas. Es curioso que esa nota se eliminara de todas las ediciones posteriores y que nuestro trabajo demuestre que Piedra de Sol no responde tanto a lo que se sugería como propósito original cuanto a una constante estética que ya estaba en la conciencia del poeta y que quizá involuntariamente fluye junto con el nacimiento del poema ${ }^{\text {. }}$.

Creemos que este detalle confirma lo que hemos dicho con palabras del autor sobre la esencia de lo poético y del misterio que siempre encierra la poesía. Y, como corolario, ratifica lo difícil que es «explicar» el sentido oculto del poema, aun cuando el mismo poeta nos haya hecho confesiones íntimas, porque la poesía siempre implica «algo que no estaba en el sentimiento original, algo que nosotros hemos creado para nombrar lo innombrable y decir lo indecible... Antes de la creación, el poeta, como tal, no existe. Ni después. Es poeta gracias al poema» (Arco, 168).

\footnotetext{
- Esta insinuación nuestra creemos no contradice lo afirmado por John M. Fein en su artículo «La estructura de 'Piedra de sol'», Revista Iberoamericana, núm. 78 (enero-marzo 1972), en cuanto a la posible oposición entre la nota y el epígrafe al cual el estudio hace referencia. Ahora bien, no pensamos que fuera suprimida de las ediciones posteriores porque la misma revelara demasiado o tendiera a deformar la opinión del lector, como sugiere Fein. Véase también el importante estudio de José Emilio Pacheco «Descripción de 'Piedra de sol'», en Alfredo Roggiano, Octavio Paz (Madrid: Editorial Fundamentos, 1979), pp. 111-124.
} 
